Gut, 1988, 29, 137-142

Leading article

\title{
Non-surgical treatment of gall stones: many contenders but who will win the crown?
}

Is gastroenterology in danger of becoming overwhelmed by a prodigality of treatments and techniques? Thirty years ago investigations comprised the biochemical analysis of blood, non-invasive radiology and a few 'function' tests needing nasogastric intubation. Therapy was often restricted to the simple decision between using a limited pharmacopoeia, or surgery. Fibreoptic endoscopy, invasive radiology and the proliferation of powerful targetted drugs have changed all this. Therapeutic alternatives abound and now instead of wondering what to do, we debate what not to do. The seductive attraction of the clinical trial all too often results in promises unfulfilled, but nevertheless has made a contribution to rational therapy. This changing scene is reflected in the many ways of managing numerous gastrointestinal disorders, such as malignant oesophageal strictures, ${ }^{1}$ peptic ulcer ${ }^{2}$ lesions of the extrahepatic biliary system ${ }^{3}$ and gall stones.

The publication in 1972 of the trail blazing paper by Danzinger and his colleagues $^{4}$ signalled the end of centuries of quackery. At last we had a genuine oral therapy for dissolving gall stones. Treatment with chenodeoxycholic acid for cholesterol gall stones was welcomed by a public ever fearful of surgery and it opened the door to the use of other agents, singly or in combination, to dissolve gall stones. Management options have been widened with the imaginative and highly skilled use of fibreoptic endoscopy to dissolve, crush and extract stones in the bile duct. To complete the picture we have emerging the added option of extracorporeal shock wave lithotripsy.

Most gastroenterologists are familiar with the considerations conducive to successful chenodeoxycholic acid therapy: radiolucent gall stones in a gall bladder that opacifies on oral cholecystography, stones not much larger than $15 \mathrm{~mm}$ in diameter and moderate symptoms. Unfortunately overall efficacy is disappointingly low, around $38 \%,{ }^{5}$ but this can be improved by careful selection of patients who will comply conscientiously and are not obese, and by ensuring that during treatment bile becomes unsaturated in cholesterol. Under these conditions successful outcome can be expected in $70-75 \%$ of patients. The non-responders are probably patients who have radiolucent pigment stones which will not respond to chenodeoxycholic acid. Surface calcium salts (phosphate, bilirubinate, carbonate) and probably also the inorganic matrix ${ }^{67}$ are responsible for the failure of some radiolucent stones to dissolve.

The optimal dose of chenodeoxycholic acid is $13-15 \mathrm{mg} / \mathrm{kg} / \mathrm{day}$, but obese patients need doses as large as $18-20 \mathrm{mg} / \mathrm{kg}$ /day before the bile becomes unsaturated. ${ }^{8}$ The use of chenodeoxycholic acid is not without problems. It causes moderate abnormalities in the liver associated analytes, diarrhoea, 
and minor increases in low density lipoprotein cholesterol. While small stones may dissolve in less than six months, stones of 5-10 mm diameter take up to 12 months to disappear and complete dissolution of $15 \mathrm{~mm}$ diameter stones requires therapy for at least two years which demands patience from physician and patient. Many attempts have been made to improve the efficacy and speed of treatment, including low cholesterol diets, administration of chenodeoxycholic acid as a single bedtime dose $\mathrm{e}^{y}$ and even combining it with phenobarbital, ${ }^{10}$ which has understandably not found favour.

Chenodeoxycholic acid can also be combined with either ursodeoxycholic acid, or Rowachol. Ursodeoxycholic acid in a dose of $8-13 \mathrm{mg} / \mathrm{kg} / \mathrm{day}$ is at least as effective as chenodeoxycholic acid in treating cholesterol stones. The indications for, and constraints on its use are the same as for chenodeoxycholic acid and it has the advantage of freedom from adverse effects or toxicity," but treatment is more expensive than with chenodeoxycholic acid. The two bile acids differ in their mode of cholesterol solubilisation: chenodeoxycholic acid dissolves cholesterol in micelles, while ursodeoxycholic acid promotes the transport of cholesterol as liquid crystals. ${ }^{12}$ Furthermore in contrast with chenodeoxycholic acid, ursodeoxycholic acid does not cause bile unsaturation by decreasing the activity of the rate limiting enzyme for hepatic cholesterol synthesis, 3-hydroxy-3methyl glutaryl coenzyme A reductase. ${ }^{13}$ A combination of chenodeoxycholic acid and ursodeoxycholic acid daily in a dose of $7.5 \mathrm{mg} / \mathrm{kg}$ and 6.5 $\mathrm{mg} / \mathrm{kg}$ respectively, has been recommended. ${ }^{14}$ Proper evaluation of this regimen in comparison to single drug therapy is now needed.

Rowachol is a preparation of six cyclic monoterpenes in olive oil. Its place in the management of cholesterol gall stones is controversial. The drug is less effective than conventional bile acid therapy, but in combination with chenodeoxycholic acid (Rowachol one capsule twice daily and chenodeoxycholic acid $7 \cdot 0-10 \cdot 5 \mathrm{mg} / \mathrm{kg} /$ day) it achieves acceptable dissolution rates. ${ }^{15}$

There are two problems which bedevil bile acid therapy for cholesterol stones: the tendency for stones to recur when treatment is discontinued and the small proportion of gall stone sufferers who are suitable for it. The proclivity to gall stone formation is most persistent. About one quarter of patients will reform stones within three years of stopping bile acid medication, after seven years half the patients have recurrent gall bladder stones $^{16}$ and by 12 years, $64 \% .{ }^{17}$ Low dose $(375 \mathrm{mg} / \mathrm{kg} /$ day $)$ chenodeoxycholic acid fails to prevent recurrence ${ }^{16}$ and the recent report of the British-Belgian Gallstone Study Group's post dissolution trial in preventing gall stone recurrence is equally discouraging, for neither $3 \mathrm{mg}$ ursodeoxycholic acid/kg/day, nor a high fibre, low refined carbohydrate diet decreased recurrence rates. ${ }^{18}$ While the newly formed stones can be redissolved with a fresh course of bile acid, the present inability to prevent the regrowth of gall stones remains a strong disincentive to the use of these drugs and provides a powerful argument for those who favour a surgical approach to the management of gall bladder stones. Our studies show that less than $30 \%$ of patients fulfill those criteria that make them acceptable for oral dissolution therapy, a figure supported by data from Rome. ${ }^{19}$ When such factors as obesity and compliance are considered, the figure may be as low as $10 \% .{ }^{20}$ It does seem as if the drugs available at present are not likely to be very important in the management of gall stones.

Two new treatment options enliven the scene: dissolution of gall stones 
with methyl tertiary butyl ether (MTBE) and extracorporeal shock wave lithotripsy. Percutaneous transhepatic catheterisation of the gall bladder can be used to instill the powerful cholesterol solvent MTBE, an ether that is liquid at body temperature, into the gall bladder. Successful gall stone dissolution occurs within hours. ${ }^{21}$ This treatment is not for the faint hearted. Nausea, vomiting, duodenal erosions, pain, haemolysis and inadvertent anaesthesia are encountered and although a microprocessor assisted infusion system has been devised to prevent gall bladder distension and overflow of MTBE into the duodenum, ${ }^{22}{ }^{23}$ it is probable that in the foreseeable future this system of management will be confined to the more specialist centres. We have seen at least one patient develop a mild, acute chemical cholecystitis. Methyl tertiary butyl ether does not dissolve pigment stones. But the percutaneous approach is attractive to the radiologist as well as to those who will seek any alternative to avoid abdominal surgery.

Of much greater appeal is the non-invasive technique of extracorporeal shock wave lithotripsy ${ }^{24}$ which is safe, sophisticated and expensive. Originally extracorporeal shock wave lithotripsy needed a large immersion water tank and general anaesthesia. Presently intravenous analgesia suffices for most patients and second generation systems as being designed without the need for the water tank, using only a compressible, moveable water bag which houses an electrode ellipsoid assembly. ${ }^{25}$ There are now many techniques for generating shock waves, including electrostatic spark discharge, electromagnetic energy and pulsed piezoelectric shock generation. Very large and very small stones and calcified stones are unsuitable. The gall bladder should be functioning radiologically. Soft cholesterol stones tend to break into large pieces and a complementary course of oral bile salts is recommended after fragmentation. Only $30 \%$ of all patients with gall bladder disease are suitable for lithotripsy, which can also be used to fragment common bile duct stones. Before extracorporeal shock wave therapy can become a widely accepted procedure, it will have to become cheaper. The problem of stone recurrence may well be a cause for anxiety.

Common bile duct stones are regarded seriously by the gastroenterologist. Until recently they were considered to be a prime indication for surgery, but as has been discussed here previously, ${ }^{26}{ }^{27}$ attitudes have changed sufficiently for a distinguished colleague to claim that 'endoscopic sphincterotomy . . . should replace surgery in most such patients with retained or recurrent stones, and appears justified in many patients who have not yet undergone cholecystectomy'. ${ }^{27}$ From the rather muted response to this comment one suspects that most surgeons accept the approach. Endoscopic sphincterotomy and stone extraction is successful in up to $90 \%$ of patients and is most likely to fail when large stones cannot be delivered through a complete sphincterotomy.

What is the correct management of common bile duct stones? Oral dissolution therapy, endoscopic sphincterotomy with or without dissolution and or extraction, percutaneous transhepatic intubation and dissolution, nasobiliary solvent infusion, T-tube infusion of solvents, T-tube extraction using the Burhenne technique, lithotripsy either extracorporeal or through an endoscope, or should the management be expectant? The many different clinical situations and the numerous techniques and solvents will surely provide a fertile source of comparative studies for many years to come. It will be some time before we can appreciate the most appropriate manage- 
ment option for a particular circumstance, but at least we do have such a variety of treatments that if one approach fails, there is always a second, or even a third alternative. The paper by Murray and his colleagues in this issue of Gut illustrates the situation well. ${ }^{28}$ They provide an account of 10 patients with choledocholithiasis in whom, after an unsuccessful sphincterotomy and stone extraction with a balloon catheter and metal basket, MTBE was introduced through a nasobiliary catheter resulting in successful dissolution and endoscopic removal of stones in eight patients.

Using MTBE in choledocholithiasis is still somewhat new and there is much greater experience with the instillation of monooctanoin to dissolve bile duct stones. ${ }^{29}$ Results with this agent have been disappointing, with unequivocal success in only $26 \%$ of patients. Monooctanoin made a positive contribution to management in a further $28 \%$ of patients. The organic matrix of gall stone comprising mucin (mucus, glycoprotein) derived from the gall bladder is an important factor in determining the outcome of gall stone dissolution by monooctanoin. ${ }^{7}$ Of much interest is 2 -mercaptoethanol, a mucolytic agent which promotes the in vitro dissolution of cholesterol stones when combined with monooctaoin. ${ }^{7}$ Other promising agents include the addition of either palmidrol, or pluronic F68 to monooctanoin (which enhances dissolution by improving the capacity of the monoglyceride to moisten the stone surface) and 1\% edetic acid (EDTA), which might aid the solubilisation of calcium..$^{30}$ Many other drugs have been used to treat retained common bile duct stones, but with limited success. ${ }^{31}$

The ingenuity of the endoscopist knows no bounds. Endoscopic lithotripsy can be carried out by mechanical, ultrasonic, or electrohydrolytic methods. Even laser technology has been applied to fragmentation of common bile duct stone..$^{32}$ All are possible, but it is yet to be shown which, if any, of the techniques are competitively safe and cost effective. These approaches will have to compete with the inherent attractiveness of the rapidly evolving extracorporeal techniques. ${ }^{33}$ Recognition of the variation in the composition of gall stones must serve as a spur to the pharmacologist to develop new compounds that can solubilise the different constituents and suggests that therapy with a tablet containing more than one agent may yet be a successful approach to the oral dissolution of gall stones. There will, however, always be the problem that such a treatment is likely to take much longer than mechanical fragmentation. We have now reached a stage where, rather unexpectedly, surgery has less of a contribution to make to the treatment of common bile duct, than gall bladder stones. This is all to the good. While in ideal circumstances the mortality of cholecystectomy is under $1 \%$, it may be considerably higher when the common bile duct is explored..$^{27}$

The answer therefore to the question posed in the title is that there can be no winner, for there is no competition. The correct non-surgical treatment for gall stone disease will depend on the individual circumstances and the aim of the clinician must be to identify the treatment which will be most appropriate for a particular patient. But the major challenge in the management of gall stones is not so much our ability to remove them from the gall bladder in situ, but to prevent their recurrence. Until this is solved, the treatment of cholelithiasis will remain very much within the domain of the surgeon.

IAN A D BOUCHIER

University of Edinburgh, Department of Medicine, Royal Infirmary, Edinburgh EH3 9YW 


\section{References}

1 Cox J, Bennett AA. Light at the end of the tunnel? Palliation for oesophageal carcinoma. Gut 1987; 28: 781-5.

2 Isenberg J, Johansson C (eds). Peptic ulcer disease clinics in gastroenterology London: W B Saunders, 1984: 13: 287-654.

3 Tytgat GNJ, Huibregtse K, Bartelsman JFWM, DenHartog Jager FCA. Endoscopic palliative therapy of gastrointestinal and biliary tumours with prostheses. Clin Gastroenterol 1986; 15: 249-71.

4 Danzinger R, Hofmann AF, Schoenfield LJ, Thistle JL. Dissolution of cholesterol gallstones by chenodeoxycholic acid. N Engl J Med 1972; 286: 1-8.

5 Maton PN, Iser JH, Reuben A, Saxton HM, Murphy GM, Dowling RH. Outcome of chenodeoxycholic acid (CDCA) treatment in 125 patients with radiolucent gallstones. Medicine 1982; 61: 85-96.

6 Freilich HS, Malet PF, Schwartz JS, Soloway RD. Chemical and morphologic characteristics of cholesterol gallstones that failed to dissolve on chendiol. The National Cooperative Gallstone Study. Gastroenterology 1986; 91: 713-8.

7 Smith BF. Dissolution of cholesterol gallstones in vitro. Gallstone matrix content and diameter, not cholesterol content, predict gallstone dissolution in monooctanoin. Gastroenterology 1987; 93: 98-105.

8 Iser JH, Maton PN, Murphy GM, Dowling RH. Resistance to chenodeoxycholic acid (CDCA) treatment in obese patients with gallstones. Lancet 1978; i: 1509-12.

9 Kupfer RM, Maudgal DP, Northfield TC. Gallstone dissolution during chenic acid therapy. Effect of bedtime administration plus low cholesterol diet. Dig Dis Sci 1987; 27: 1025-9.

10 Coyne MJ, Bonorris GG, Chung A, Goldstein LI, Lahana D, Schoenfield LJ. Treatment of gallstones with chenodeoxycholic acid and phenobarbital. N Engl J Med 1975; 292: 604-7.

11 Bachrach WH, Hofmann AF. Ursodeoxycholic acid in the treatment of cholesterol cholelithiasis. Dig Dis Sci 1982; 27: 833-6.

12 Fromm H. Gallstone dissolution therapy. Current studies and future prospects. Gastroenterology 1986; 91: 156()-7.

13 Angelin B, Ewerth S, Einarsson K. Ursodeoxycholic acid treatment in cholesterol gallstone dissolution: effects on hepatice 3-hydroxy-3-methylglutaryl coenzyme A reductase activity, biliary lipid composition, and plasma lipid levels. J Lipid Res 1983; 24: 461-8.

14 Roehrkasse R, Fromm H, Malavolti M, Tunuguntla AK, Ceryak S. Gallstone dissolution treatment with a combination of chenodeoxycholic and ursodeoxycholic acids. Studies on safety, efficacy and effects on high lithogenicity, bile acid pool and serum lipids. Dig Dis Sci 1986; 31: 1032-40.

15 Ellis WR, Somerville KW, Whitten BH, Bell GD. Pilot study of combination treatment for gallstones with medium dose chenodeoxycholic acid and a terpene preparation. $\mathrm{Br} \mathrm{Med} \mathrm{J}$ 1984; 289: 153-6.

16 Marks JW, Lan S-P, the Steering Committee and the National Cooperative Gallstone groups. Low dose chendiol to prevent gallstone recurrence after dissolution therapy. Ann Intern Med 1984; 100: 376-81.

17 Villanova N, Bazzoli F, Frabboni R, et al. Gallstone recurrence after successful oral bile acid treatment: a follow-up study and evaluation of long term post-dissolution treatment [Abstract]. Gastroenterology 1987; 92: 1789.

18 Hood K, Gleeson D, Ruppin DC, Dowling RH, and the BBGSG. The British/Belgian Gallstone Study Group's (BBGSG) post-dissolution trial [Abstract]. Gut 1987; 28: A1359.

19 Rome Group for the Epidemiology and Prevention of Cholelithiasis (GREPCO). Radiologic appearance of gallstones and its relationship with biliary symptoms and awareness of having gallstones. Observations during epidemiological studies. Dig Dis Sci 1987; 32: 349-53.

20 Whiting MJ, Bradley BM, Watts J McK. Chemical and physical properties of gallstones in South Australia: complications for dissolution treatment. Gut 1983; 24: 11-5.

21 Allen MJ, Borody TJ, Bugliosi TF, May GR, La Russo NF, Thistle JL. Rapid dissolution of gallstones by methyl tert-buryl ether. Preliminary observations. $N$ Engl J Med 1985; 312: 217-20.

22 Zakko SF, Hofmann AF. Microprocessor assisted solvent transport system for infusion of methyl tert-butyl ether (MTBE) or other gallstone (GS) solvents into the gallbladder (GB). Gastroenterology 1987; 92: 1794.

23 Zakko SF, Hofmann AF, Schteingart C, van Sonnenberg E, Wheeler HO. Percutaneous gallbladder stone dissolution using a microprocessor assisted solvent transport (MAST) system. Gastroenterology 1987; 92: 1794. 
24 Sauerbruch T, Delius M, Paumgartner G, et al. Fragmentation of gallstones by extracorporeal shock waves. $N$ Engl J Med 1986; 314: 818-22.

25 Staritz M, Floth A, Rambow A, Buess G, Wilpert D, Schild F. Extracorporeal shock waves (device of the second generation) for therapy of large common bile duct stones; causes and problems. Gastroenterology 1987; 92: 1652.

26 Dowling RH. Management of stones in the biliary tree. Gut 1983; 24: 599-608.

27 Cotton PB. Endoscopic management of bile duct stones (apples and oranges). Gut 1984; 25 : 587-97.

28 Murray WR, LaFerla G, Fullarton GM. Choledocholithiasis - in vitro stone dissolution using methyl tertiary butyl ether (MTBE). Gut 1988; 29: 143-5.

29 Palmer KR, Hofmann AF. Intraductal monooctanoin for the direct dissolution of bile duct stones: experience in 343 patients. Gut 1986; 27: 196-202.

30 Leuschner U. Endoscopic therapy of biliary calculi. Clin Gastroenterol 1986; 15: 333-8.

31 Neoptolemos JP, Hofmann AF, Moosa AR. Chemical treatment of stones in the biliary tree. Br J Surg 1986; 73: 515-24.

32 Nishioka NS, Levins PC, Murray SC, Parrish JA, Anderson RR. Fragmentation of biliary calculi with durable dye lasers. Gastroenterology 1987; 93: 250-5.

33 Ferruci JT. Biliary lithotripsy: what will the issues be? Am J Roentgenol 1987; 149: 227-31. 